\title{
Neuropsychiatric Symptoms Related to Cholinergic Deficits in
}

\section{Parkinson's Disease}

Santiago Perez-Lloret ${ }^{1}$, María Cecilia Peralta ${ }^{2}$, Francisco J. Barrantes ${ }^{3}$

${ }^{1}$ Institute of Cardiology Research, University of Buenos Aires, National

Research Council (CONICET-ININCA), Marcelo T. de Alvear 2270, C1122AAJ

Buenos Aires, Argentina.

2Parkinson's disease and Movement Disorders Clinic, Neurology Department, CEMIC University Hospital. Elias Galvan 4102, C1431. Buenos Aires, Argentina.

${ }^{3}$ Laboratory of Molecular Neurobiology, Institute for Biomedical Research, UCA-

CONICET, Faculty of Medical Sciences, Av. Alicia Moreau de Justo 1600, C1107AFF Buenos Aires, Argentina.

Text: Words $=4700$, Abstract $=189$, References $=99$, Tables $=3$.

Conflict of interests:The authors declare no conflict of interests to disclose.

Address for correspondence:

Santiago Perez-Lloret MD PhD CPI, Institute of Cardiology Research, Marcelo T. de Alvear 2270

(C1122AAJ) Buenos Aires. Argentina

Telephone/Fax $=+54+11$ 4508-3880/1

Email=santiagopl@conicet.gov.ar 


\section{Abstract}

Given its ability to explain the most frequent motor symptoms of Parkinson's disease (PD), degeneration of dopaminergic neurons has been considered one of the disease's main pathophysiological features. Several studies have shown that neurodegeneration also affects noradrenergic, serotoninergic, cholinergic and other monoaminergic neuronal populations. In this work, the characteristic contribution of cholinergic deficits to cognitive dysfunction, psychosis and sleep disturbances in PD and their treatment will be explored. Important neurophysiological processes at the root of several motor and cognitive functions remit to cholinergic neurotransmission at the synaptic pathway and circuital levels. The bulk of evidence highlights the link between cholinergic alterations and the aforementioned symptoms. The pathophysiology of these symptoms is related to degeneration of cholinergic nuclei, most importantly the nucleus basalis magnocellularis and the pedunculo-pontine nucleus. Rivastigmine, a drug that increases cholinergic tone by inhibiting the enzyme cholinesterase, is effective for dementia, whereas the use of Donepezil is still in the realm of investigation. Evidence on the clinical effects of these drugs for psychosis and REM-sleep disturbances is still weak. Anticholinergic drugs should be used with caution in PD, as they may aggravate these cholinergic symptoms.

Keywords: Parkinson's Disease, acetylcholine, neurodegeneration, treatment, pathophysiology 


\section{Introduction}

Parkinson's disease (PD) is a progressive neurodegenerative disorder affecting about 1 person out of every 1,000 in their fifth decade and 19 out of every 1,000 in their eighth decade or older [1]. Its principal epiphenomenological clinical symptoms are abnormal involuntary movements, bradykinesia, rigidity and tremor. Patients also frequently display non-motor symptoms, including cognitive impairment, mood disorders, sleep alterations, dysautonomia and hallucinations, among other symptoms [2].

Histopathological changes are mainly, but not exclusively, characterized by the progressive loss of the nigrostriatal dopaminergic pathway and of the source dopaminergic neurons in the substantia nigra pars compacta, which explain the most typical motor symptoms [3]. Administration of levodopa to parkinsonian patients has been considered the most effective symptomatic treatment for the last 40 years [4].

At the cellular and molecular levels, neuronal death may be preceded by a series of dysfunctional states, including loss of redox control, alteration of Iysosomal activity, abnormal protein control mechanisms in the endoplasmic reticulum (ER) and perturbation of the ER-Golgi trafficking mechanisms. These pathologies are closely intertwined with one of the hallmarks of the disease, namely the abnormal accumulation of misfolded protein aggregates [5]. Lewy bodies constitute a characteristic pathological finding, second only to the neurofibrillary tangles in Alzheimer's disease (AD). Early work identified the immunoreactivity of the Lewy bodies with antibodies against the presynaptic protein $\alpha$-synuclein [6].One major target of $\alpha$-synuclein is Rab1, a key 
component of the ER-Golgi trafficking pathway [7]. ER stress has been invoked as a possible major disruptive mechanism, leading to an adaptive reaction known as the unfolded protein response [8].This response may be cytoprotective when activated to a moderate level, but is deleterious at a higher level, triggering in turn the apoptotic death of the damaged neuron $[9,10]$. PD may also be considered a synaptopathy, i.e. abnormal synaptic connectivity compromising nigrostriatal pathways and intra-striatal interneuronal connections, presumably most apparent at the initial stages of the disease. Mutations in the $\alpha$-synuclein gene cause familial forms of PD and dementia with Lewy bodies. Synaptic accumulation of $\alpha$-synuclein is accompanied by the redistribution of the synaptic SNARE proteins SNAP-25, syntaxin-1 and synaptobrevin-2, as well as by an age-dependent reduction in dopamine release [11].

The striatum is the most important input nucleus of the basal ganglia. The principal source of afferents is layer 5 of the cerebral cortex, conveying glutamatergic (Glu) excitatory synapses. Motor areas (4 and 6 plus supplementary motor area) together with the primary somatosensory cortex follow, also with Glu neurotransmission. The second major striatal input is dopaminergic (DA), stemming from the substantia nigra A9 cell group. There are many features of PD that are unresponsive to levodopa, such as gait disorders and cognitive impairment or dementia, indicating the involvement of other neurotransmitter systems [12]. In this regard, recent evidence suggests degeneration of adrenergic, serotoninergic and cholinergic neurons, among others [12]. 
The importance of cholinergic dysfunction in the physiopathology of many PD features cannot be overemphasized. For example, in a recent study in 137 PD patients, cholinergic denervation could be related to REM behavior disorder, fall history, gait disorders, psychosis and cognitive dysfunction [13, 14]. In this chapter we review the pathophysiology and treatment of neuropsychiatric symptoms originating from cholinergic degeneration, namely dementia, psychosis and sleep disturbances. A summary of cholinergic neurotransmission in health will precede the sections on cholinergic deficits in PD.

Bibliographical references were searched in Pubmed by the following string: (acetylcholine OR cholinergic) AND Parkinson's disease. Articles in English, Spanish or French were retrieved. Reference sections from retrieved papers were also explored for data-base enrichment.

\section{Cholinergic neurotransmission in health}

Acetylcholine (ACh) is an ubiquitous, small molecular weight neurotransmitter which plays a pivotal role in chemical neurotransmission in the central (CNS) and peripheral nervous system (PNS). In the brain, ACh mediates distant signaling through projection neurons and local signaling via interneurons. The type of message conveyed by ACh depends on a variety of factors, including site of release, the localization of the target neurons, the target receptor subtypes [15] and the status of the target cells at the time of release. Furthermore, ACh signaling may be circumscribed to the synapse or result from the de-localized diffusion of the neurotransmitter in the extracellular milieu and binding to non-synaptic sites $[16,17]$. In terms of gross anatomical 
brain regions it is safe to state that $A C h$ affects brain in its entirety. A recent review (ref.[18]) meticulously dissects current knowledge on the anatomy of cholinergic projections, summarized in two main tracks: i) the brainstem; and ii) the magnocellular basal forebrain- cholinergic systems. The former, as worked out by immunochemical techniques [19], involves neuronal soma located in the pedunculo-pontine tegmental nucleus (PPN) and the laterodorsal pontine tegmentum (LDT) and projecting to the thalamus, basal ganglia, the basal forebrain and to a much lesser extent, the cerebral cortex. The basal forebrain cholinergic system comprises neurons located in the medial septal nucleus (MS), the vertical and horizontal limbs of the diagonal band of Broca, and the nucleus basalis magnocellularis (NBM, the nucleus basalis of Meynert in humans), which send projections to neocortex, entorhinal cortex, limbic cortices, cingulate cortex and hippocampus. Cholinergic fibers in cortex appear not to be associated with postsynaptic densities, a fact that has been linked with the hypothesis that cholinergic transmission may not be synaptic but may involve modulation of target neurons via diffusion, so-called volume transmission [16].

From the standpoint of the target receptors, ACh neurotransmission is mediated through two entirely different types of receptor proteins and ensuing molecular mechanisms, i.e. the metabotropic 7-transmembrane domain (TM) muscarinic AChRs and the ionotropic pentameric nicotinic nAChRs (See Table 1 for a summary). The former are members of the G protein-coupled superfamily of receptors, which possess 7-transmembrane segments and mediate intracellular signals associated with metabolic cascades. The nAChRs, on the other hand, are members of the superfamily of pentameric ligand-gated ion channels (pLGIC), a collection of neurotransmitter receptors which also 
includes $\mathrm{Y}$-amino butyric acid (GABA-A, GABA-C), glycine, serotonin (5-HT3) and bacterial homologs $[20,21]$.

The metabotropic mAChRs are coupled to different types of $G$ proteins, e.g. Gi/otype (M2 and M4 subtypes of mAChRs) of G proteins that negatively couple to adenylate cyclase or $\mathrm{G}_{q}$ proteins (M1, M3 and M5 subtypes of mAChRs), which convert the cholinergic signal into metabolic cascades [22]. Presynaptic mAChRs (M2, M4 subtypes) are largely inhibitory and perform this function partly as inhibitory autoreceptors on cholinergic terminals [23]. The M2 subtype is the predominant autoreceptor in the hippocampus and cerebral cortex, whereas M4 is the main subtype in the striatum $[15,22,24]$. Postsynaptic mAChRs can be either inhibitory (M2, M4) or excitatory (M1, M3, M5) $[15,24]$.

The ionotropic, fast-signaling nAChRs are composed of five polypeptide subunits organized pseudo-symmetrically around a central pore [25]. Each subunit contains an extracellular domain, four hydrophobic transmembrane segments arranged in the form of three concentric rings around the pore and a short extracellular carboxy-terminal domain. nAChRs are characteristically involved in the rapid "phasic" effects of ACh under conditions of brief release / high local concentration of the neurotransmitter, but they also operate under the low, tonic ACh release or mimicking systemically applied cholinergic drugs [16], a condition which may be particularly relevant to cholinergic neurotransmission -and/or its modulation- in the striatum.

Muscle-type nAChRs are expressed in the PNS and neuronal-type nAChRs in both PNS and the CNS as well as in other non-neural tissues such as immune cells, lymphocytes, lung epithelium and other tissues [26]. In the 
CNS, the nAChR is present in various combinations of subunits $(\alpha 4, \alpha 5, \alpha 6, \alpha 7$, $\alpha 9, \alpha 10$ and $\beta 2$ )[27], the two most abundant ones being the hetero-pentameric receptor formed by $\alpha 4$ and $\beta 2$ subunits and the homo-pentameric receptor formed exclusively by $\alpha 7$ subunits. The deficit of some of the nAChR subunits in PD has been explicitly explored [28]. The two predominant forms of the nAChR, the $\alpha 4 \beta 2$ and the $\alpha 7$ oligomers, are also strongly expressed in the striatum, accompanied by the $\alpha 6 \beta 2$ form[29]. It is not clear whether other subunits are present in the heteromeric nAChRs. The $\alpha 4 \beta 2$ and $\alpha 6 \beta 2$ nAChRs in the striatum are localized at the dopaminergic terminal, the predominant target undergoing degeneration in PD. The $\alpha 4 \beta 2 \mathrm{nAChR}$ is also found in striatal GABAergic inhibitory interneurons [30].

The $\alpha 7 \mathrm{nAChR}$ exhibits certain functional properties that distinguish it from other nicotinic receptors: a) fast desensitization kinetics, b) unusually high $\mathrm{Ca}^{2+}$ permeability and c) high affinity for binding $\alpha$-bungarotoxin [27, 31]. In most regions of brain the $\alpha 7 \mathrm{nAChR}$ is found presynaptically, where it modulates enhanced neurotransmitter release of various other neurotransmitters, including DA, 5-HT, glutamate and GABA; and postsynaptically, where it generates postsynaptic currents [32, 33]. In addition, the peri-synaptic presence of the receptor has also been demonstrated, where it modulates neuronal activity, presumably by an unconventional mechanism involving diffusion of the natural neurotransmitter and binding to non-synaptic sites [16]. In the striatum, the $\alpha 7 \mathrm{nAChRs}$ are found in cortical glutamatergic excitatory afferents [32].

Cholinergic mechanisms are intimately linked to cognitive functions associated with cortical and hippocampal brain anatomical regions. Working 
memory, spatial and episodic memory acquisition, storage, maintenance and retrieval, attention and other neurophysiological processes at the root of neural information and cognitive functions remit to ACh neurotransmission at synaptic, pathway and circuital levels.

\section{Neuropsychiatric symptoms resulting from cholinergic degeneration in PD}

A summary of the brain cholinergic nuclei exhibiting signs of denervation in PD and their neuropsychiatric correlates is presented in Table 2. In this section the contributions of cholinergic degeneration to the physiopathology of cognitive impairment, psychosis and sleep disturbances in PD will be summarized.

\subsection{Cognitive impairment and mood disorders}

The physiopathology of PD Dementia (PDD) is complex and involves severe dopaminergic and cholinergic deficits, the main pathological drivers of cognitive decline being a synergistic effect between a-synuclein and AD's pathology [34]. Only cholinergic deficits will be reviewed in this section.

\subsubsection{Alteration in cholinergic receptors expression or function in cognitive} impairment in PD

Because of their distribution in brain anatomical regions associated with cognitive processes, various subtypes of $\mathrm{nAChR}$ have been invoked as being associated with abnormal cognitive processes. The $\alpha 7 \mathrm{nAChR}$ is highly expressed in the hippocampus, a region particularly affected in cognitive 
disorders [27, 35, 36, 37], as recently reviewed in ref. [38], whereas a massive loss in cerebral cortex of the other most abundant type of CNS nAChRs, the

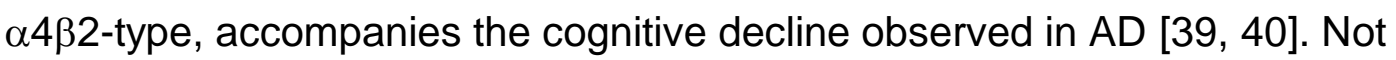
surprisingly, alterations in memory and cognition associated with $\mathrm{nAChRs}$ have also been reported in pathological states other than $A D$, such as schizophrenia [41]. The various functions afflicted in PD have been associated with $n A C h R$

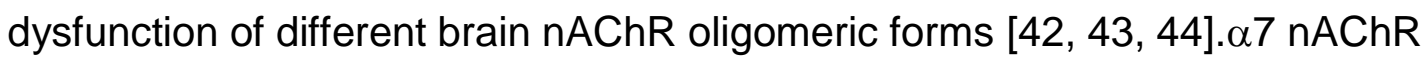
ligands are a subject of intense research in diseases affecting cognitive functions, especially the subclass of ligands termed positive allosteric modulators (PAMs, see reviews in ref.[45]). It is a group of compounds that enhance recognition memory and cognitive improvement in animal models (e.g. ref. $[46,47])$.

Muscarinic receptors are also implicated in cognitive disturbances. Antagonists such as scopolamine perturb the performance of cognitive tasks in animal models [48] and even lead to extreme cognitive disturbances with delirium at higher doses [49]. This condition has also been reported in children after application of postsurgical transdermal patches to ameliorate nausea and motion sickness [50] and in the elderly, who are particularly vulnerable to even modest levels of antimuscarinic drugs due to their cumulative effects [51].

Several lines of evidence link brain nicotinic nAChRs, the $\alpha 7$ in particular, with the development of neurodegenerative disease with cognitive impairments, like AD [45]. The greater the depletion of cholinergic neurons and associated cholinergic pathways in cognitive-associated brain areas such as the neocortex and hippocampus, the more severe the associated dementia, suggesting a relationship between the clinical manifestations and the level of cholinergic 
decline $[52,53]$. Cholinergic pathways are associated with the processes of learning and memory, and nicotinic agonists and cholinomimetics in general have been used as therapeutic agents providing symptomatic improvements in cognitive impairment $[54,55,56,57,58]$. This constitutes the basis of therapeutic approaches aiming at $\alpha 7 \mathrm{AChR}$ activation with selective agonists.

\subsubsection{Data from studies in PD patients}

The involvement of ACh pathways in PD is further exemplified by the results of a recent trial by Park and colleagues [59]. White matter hyperintensities in the cholinergic pathways were assessed by means of the Cholinergic Pathways Hyperintensities Scale (CHIPS) using 3.0 Tesla magnetic resonance. Patients with AD ( $n=20)$, PDD ( $n=21)$ and Dementia with Lewy Bodies (DLB, $n=17$ ) were compared with a group of 20 healthy controls. Results showed that the CHIPS score was correlated with MMSE, SOB scores of the Clinical Dementia Rating, and verbal and visuospatial memory domains in demented patients.

Degeneration of the NBM appears to be highly correlated with PDD [60]. A recent study showed that PD patients with mild cognitive impairments (PD$\mathrm{MCl}$ ) who would develop PDD during follow-up had greater degeneration of the substantia innominata, where the NBM is located [61]. In this study, 51 PD-MCI were followed for a minimum of 2 years, during which PDD was diagnosed in 15 cases. Greater grey matter loss in the prefrontal area was also observed in subjects developing PDD. Loss of neurons in the substantia innominata was observed in early stages of the disease, and was further accentuated in PDD. 
Recent results in post-mortem analyses of brains from demented and non-demented PD patients confirmed these results. In the study by Hall and colleagues, stereological analyses of the A9 and A10 dopaminergic neurons and $\mathrm{Ch} 1, \mathrm{Ch} 2$ and $\mathrm{Ch} 4$ cholinergic neurons located in the basal forebrain, along with an assessment of $\alpha$-synuclein pathology in these regions and in the hippocampus, were performed in six demented and five non-demented PD patients and five age-matched control individuals with no signs of neurological disease [62]. Choline acetyltransferase (ChAT) activity in the hippocampus and frontal cortex was also measured in a different set of eight demented and eight non-demented PD patients, as well as in the same areas of eight age-matched controls. Stereological analyses showed a significant $54 \%$ reduction in the NMB of PDD compared to controls and a non-significant reduction of $30 \%$ in nondemented PD. No differences were observed in other cholinergic regions. Furthermore, the density of ACh neurons in the NBM correlated inversely with the severity of dementia. ChAT activity, a measure of the presence of cholinergic terminals in a given brain region, was reduced in the hippocampus of PD with dementia compared to non-demented patients and controls. Interestingly, neocortical ChAT activity was reduced in the neocortex of both demented and non-demented PD compared to controls. Finally, $\alpha$-synuclein pathology and Lewy-body deposition in the basal forebrain of patients with PDD were more severe than in non-demented patients, thus suggesting the possible role of $\alpha$-synuclein aggregation in the development of cortical and hippocampal cholinergic dysfunction.

The diminution in the density of the $\alpha 4 \beta 2$ nAChR in the CNS has been recently correlated with cognitive impairments in non-demented PD patients 
[63]. Previous studies had revealed reduced binding to these receptors in PD brains, and some preliminary findings suggest that the lower density of these receptors might correlate with cognitive impairments. In this study, 25 nondemented PD patients underwent a 5-[123I]iodo-3-[2(S)-2-azetidinylmethoxy] pyridine (5-I-A-85380) SPECT to visualize $\alpha 4 \beta 2 \mathrm{nAChRs}$ and cognitive testing with the CERAD (Consortium to Establish a Registry for Alzheimer's Disease) battery to identify domains of cognitive dysfunction [63]. Results showed significant correlations between performance of the CERAD subtests Boston Naming Test (a specific test for visual perception and for detection of wordfinding difficulties) and Word List Intrusions (a specific test for learning capacity and memory for language information) with the density of $\alpha 4 \beta 2 n A C h R s$ at the right superior parietal lobe cortex and the left thalamus, and left and right posterior subcortical regions.

An interesting question is whether the alteration of the NBM is the same as that found in AD. NBM degeneration is comparable or even more intense in PD compared to the latter, yet the clinical characteristics of the two dementias differ significantly. Some authors have suggested that the divergence may be connected to possible differences in the degree to which subsections of the NBM are affected [64], but this hypothesis remains to be studied.

Depression can precede dementia, or at least depressed patients are at greater risk of developing PDD [65]. In a recent study, neocortical cholinergic innervation was assessed in 12 non-demented PD patients, 6 PDD and 10 normal control patients [66] by means of dynamic PET scanning of previously injected $\left[{ }^{11} \mathrm{C}\right]$ methyl-4-piperidinyl propionate radioligand, a selective substrate for the enzyme AChE. Pooled analyses demonstrated a significant inverse 
correlation between cortical AChE activity and Cornell Scale for Depression in Dementia scores $(r=0.5, p=0.007)$. The correlation remained significant when only PD patients were assessed, in whom AChE activity also correlated with the MMSE score. Recent evidence suggests that the early involvement of the posterior neocortex and visuoperceptual impairment may be risk factors for the rapid symptomatic progression and dementia in PD [67].

\subsubsection{Cognitive dysfunction as a side-effect of cholinergic drugs}

In the light of the evidence reviewed above, it is not surprising that drugs interfering with cholinergic function have profound effects on cognitive function in PD. Muscarinic receptor blockers can cause acute confusion, dementia and chronic intellectual impairment [68]. In a study with trihexyphenidyl, an oral anticholinergic agent, clinical disability, cognitive assessment and measurements of cerebral blood flow (rCBF) and oxygen metabolic rate (rCMRO) were performed in 6 PD before and after administration of the drug for 7 weeks at $6 \mathrm{mg} /$ day [69]. Results showed improvements in motor symptoms without evident changes in cognitive function. Cortical and striatal rCBF and rCMRO2 were significantly decreased, a typical finding in PDD [70].

\subsection{Psychosis and delirium}

Visual hallucinations (VHs) are frequently reported by PD patients [2]. Besides the effect of dopaminergic medication, anticholinergics are associated with VHs even in patients without PD.

\subsubsection{Data from studies in PD patients}


In a recent study, inhibitory cholinergic activity in the CNS was measured by means of the short-latency afferent inhibition (SAI) technique in 10 nondemented PD patients with VHs, in 12 non-demented PD patients without VHs and in 11 age-matched healthy controls [71]. Results showed reduced SAI in patients with VHs, which was otherwise normal in patients without hallucinations. In addition, patients with VHs showed more frequent $\mathrm{MCI}$ and had reduced values in some cognitive function tests. The authors speculated that these results might be related to diminished neocortical cholinergic input from the NBM.

\subsubsection{Delirium}

Characterized by an acute and fluctuating disturbance in attention and awareness accompanied by an additional disturbance in cognition, delirium is more frequent in PD than in the general population [72]. Cholinergic deficiency is one of the most frequently found abnormalities in delirium. In a recent study, the association between exposure to anticholinergic drugs and delirium was studied in a database of more than 16.000 PD patients [73]. Results showed that $57.8 \%$ of PD patients were prescribed non-PD medications with moderate to very strong anticholinergic potential. Subjects exposed to anticholinergic polypharmacy had increased risk of delirium (adjusted OR: 1.61, 95\% Cl: 1.082.40).

\subsection{Sleep disturbances}

Sleep disturbances are common disabling non-motor features of PD that have a detrimental effect on health-related quality of life [2].Activation of the 
PPN is capable of inducing REM sleep [74] and degeneration of cholinergic neurons in the basal forebrain and brainstem is one of the factors resulting in a reduction in REM sleep and REM-sleep Behavior Disorder (RBD) [75]. RBD is characterized by a loss of normal muscle atonia during REM sleep and dreamenacting behavior. RBD occurs in $0.5 \%$ of the general population, but is considered to be a risk factor for synucleinopathies and even as a pre-motor sign of PD [76].

\subsubsection{Data from studies on animal models}

The effects on REM sleep of drugs acting on different monoaminergic systems have been explored in the MPTP mouse model of PD [77]. The objective of the study was to assess the effects of these drugs on sleep/wakefulness patterns, measuring the amount of REM sleep (or paradoxical sleep -PS-). Arecoline, a muscarinic agonist, increased the amount of PS in the MPTP-treated mice but not in the controls, probably reflecting supersensitivity in the former.

\subsubsection{Data from studies in PD patients}

Cholinergic function has been recently evaluated in PD patients with or without RBD by means of short latency afferent inhibition (SAl), a transcranial magnetic stimulation protocol able to test an inhibitory cholinergic circuit in the human brain [78]. In this study, 10 PD patients with RBD diagnosis by polysomnography, 13 patients without the disorder and 10 healthy controls were enrolled. In addition to SAI, neuropsychological examination was also performed. SAI was reduced in PD patients with RBD compared to unaffected 
$\mathrm{PD}$ and healthy controls. Interestingly, $\mathrm{MCl}$ was more frequent in the former, and cognitive parameters correlated with SAI. These findings indicate that cholinergic dysfunction may play an important role in RBD in PD.

\section{Symptomatic treatment of cholinergic deficits in PD}

The idea that enhancing cholinergic tone might be a first-line therapeutic strategy for cholinergic symptoms is logical and appealing. In this section, clinical use of cholinergic tone manipulation at the brain level by pharmacological or neurosurgical approaches will be explored. Other noncholinergic treatments will be (briefly) mentioned for the sake of completeness.

\subsection{Cognitive impairment}

A recent systematic review and meta-analysis suggested that inhibitors of cholinesterase are effective in the treatment of cognitive impairment in patients with PD [79].The systematic search yielded three studies involving donepezil and one involving rivastigmine. The EXPRESS study included 541 patients with PDD who were randomly administered $12 \mathrm{mg}$ rivastigmine or placebo and followed up for a mean of 24 weeks [80]. The study by Dubois et al. included 355 patients with PDD receiving $5 \mathrm{mg}$ donepezil10 $\mathrm{mg}$ donepezil, or placebo, followed up for a mean duration of 24 weeks [81]. The study by Ravina et al. was a crossover study in which 22 patients with PDD were randomized to receive either $10 \mathrm{mg} /$ day donepezil followed by placebo, or placebo followed by $10 \mathrm{mg} /$ day donepezil for a mean follow-up of 10 weeks [82]. Results showed that these drugs significantly slowed MMSE decline $(M D=-1.123,95 \%$ $\mathrm{Cl}=-1.638$ to $-0.608 ; \mathrm{p}=0.001 ; \mathrm{I}=44.6 \%)$, and ADAS-cog $(S M D=-0.266,95 \%$ 
$\mathrm{Cl}-0.399$ to $-0.133 ; \mathrm{p}<0.0001 ; \mathrm{I} 2=0 \%$ ). Interestingly, the death rate was lower in treated patients than in those receiving a placebo $(\mathrm{OR}=0.295,95 \% \mathrm{Cl} 0.108$ to $0.806 ; p=0.017 ; 12=0 \%)$. Tremor and adverse drug reactions in general were more frequent with cholinesterase inhibitors. A summary of these studies is presented in Table 3.

Long-term safety of rivastigmine was studied in a 76-week, prospective, openlabel, randomized study of 583 PD patients aged 50 to 85 years old [83].

Patients were randomly assigned rivastigmine $12 \mathrm{mg} / \mathrm{d}$ capsules or $9.5 \mathrm{mg} / 24 \mathrm{~h}$ patches. Primary outcomes included incidence of, and discontinuation due to, predefined adverse events (AEs) potentially arising from worsening of PD. Incidence of predefined AEs was $36.1 \%$ for capsules vs $31.9 \%$ for patch. Discontinuation due to worsening of motor symptoms was observed in $4.4 \%$ and $2.4 \%$ for capsule/patch respectively; tremor in $24.5 \%$ vs $9.7 \%$. Authors argued that these figures were in the range expected due to the natural progression of Parkinson's disease. Rivastigmine is considered to be "Clinically Useful" for the treatment of dementia in PD according to the latest review of the Movement Disorder Society Evidence-Based Medicine Task Force [84]. Use of donepezil is considered "Investigational" [84].

The efficacy and safety of rivastigmine for the treatment of minimal cognitive impairment in PD (PD-MCI) have been explored in a recent study [85]. Patients with PD-MCI ( $\mathrm{n}=28)$ were enrolled in a 24-week, randomized, double-blind, placebo-controlled, crossover, single-site study of the rivastigmine transdermal patch. The primary outcome measure was the Alzheimer's Disease Cooperative Study-Clinical Global Impression of Change (ADCS-CGIC). Twenty-six participants (92.9\%) completed both study phase assessments, and $23(82.1 \%)$ 
completed both phases on study medication. The CGIC response rate demonstrated a non-significant difference favoring rivastigmine.

In a recent study, patients with PDD or PD-MCI were compared to controls and studied before and after a 3-month therapy with rivastigmine patch [86]. At baseline, patients showed reduced spontaneous brain activity in regions important for motor control (e.g. caudate, supplementary motor area, precentral gyrus, thalamus), attention and executive functions (e.g. lateral prefrontal cortex), and episodic memory (e.g. precuneus, angular gyrus, hippocampus). Spontaneous brain activity deficits in the left premotor cortex, inferior frontal gyrus, and supplementary motor area were restored such that the activity was increased post-treatment compared with baseline and was no longer different from controls. These results are in line with a potential restoration of cortical cholinergic tone from the NBM induced by the drug.

Antimuscarinic drugs have a well-known deleterious effect on cognitive function [68], which has been confirmed in PD by a study measuring cerebral blood flow and oxygen metabolic rate after treatment with trihexyphenidyl [69]. These parameters are markers for dementia in PD [70]. Therefore, antimuscarinic drugs should be avoided in patients with cognitive impairments.

Memantine, a channel blocker of the N-methyl-d-aspartate (NMDA) type of glutamate receptors, has been prescribed for Alzheimer's disease patients, and could possibly be used for the treatment of PDD who cannot tolerate cholinesterase inhibitors, but its efficacy has been poorly documented [87]. 


\subsection{Psychosis, delirium and sleep disturbances}

The management of psychosis should start by withdrawal of potential offending drugs, anticholinergics and tricyclic antidepressant in particular [87]. Quetiapine in small doses might also be used if drug withdrawal fails [87]. Anecdotal evidence suggests interesting clinical effects with donepezil [88], and there is an ongoing randomized, double-blind, placebo-controlled trial with donepezil for this indication [89].

Withdrawal of anticholinergic drugs is also the first therapeutic measure for delirium. Cholinesterase inhibitors do not appear to be effective for delirium in older adults [90]; however, there are no studies in PD patients.

RBD symptoms were improved by rivastigmine in two small case series of patients with DLB [91]. Further results in PD are awaited. The most commonly used RBD treatments include low-dose clonazepam or high-dose melatonin taken orally at bedtime [92].

The potential effects of PPN DBS on sleep and somnolence were explored in a pilot study involving 2 PD subjects with intractable gait dysfunction [93]. Lowfrequency stimulation of the PPN area increased alertness, whereas highfrequency stimulation induced non-REM sleep. In addition, the sudden withdrawal of the low-frequency stimulation was consistently followed by REM sleep episodes in one of the patients.

\section{Discussion}


Cholinergic deficits are common in PD and contribute to motor disturbances including gait dysfunction and non-motor symptoms like cognitive impairment, dementia, mood abnormalities, psychosis and sleep disorders [14, 94]. It is therefore logical to hypothesize that increasing cholinergic tone might be a first-line strategy for the treatment of these symptoms. The bulk of evidence suggests that administering inhibitors of the enzyme cholinesterase and/or withdrawing drugs with cholinergic antagonizing effects, could be effective for treating cognitive impairment, psychosis and sleep disturbances in PD. Interestingly, cholinesterase inhibitors have also been found to be effective for gait impairment and falls [95, 96], which are also related to cholinergic degeneration [97, 98].

Several pieces of evidence suggest that rivastigmine may be considered pivotal for the treatment of PDD [79]. The evidence is weaker for PD patients with minimal cognitive impairment [85]. These patients might obtain some benefit from this type of drug, but further evidence is needed before any concrete claims can be made in this connection.

Withdrawing anticholinergic drugs is the first step in the management of psychosis and delirium in PD [87]. If further treatment is needed, cholinesterase inhibitors might also offer some benefit in the former, as suggested by anecdotal evidence. A randomized, double-blind, placebo-controlled trial with donepezil is underway. Delirium might not respond to these drugs, but no study on PD is available. Case reports also suggest that these drugs might be beneficial for RBD, at least in patients with Lewy Body Dementia [91]. Trials in $\mathrm{PD}$ are still lacking. 
There are, however, certain issues that will need to be addressed by future studies. Firstly, the safety of cholinesterase inhibitors should be more thoroughly explored. Theoretically, these drugs could worsen parkinsonian motor symptoms by further misbalancing ACh-DA tone in the striatum. Although short-term trials have not disclosed any such effects and one 1.5-year study showed results that could be considered in line with normal disease progression [83], further studies comparing disease progression in patients under these treatments with untreated controls are needed to dispel any doubts on the matter.

Psychosis and related sleep disturbances might also benefit from cholinesterase inhibitors, as suggested by low-quality evidence [87] or by evidence from other diseases [99]. Studies are urgently needed for these domains, as actual treatments either have low efficacy or are unsafe. 


\section{References}

1. Pringsheim T, Jette N, Frolkis A et al. (2014) The prevalence of Parkinson's disease: a systematic review and meta-analysis. Mov Disord 29:1583-1590

2. Chaudhuri KR, Schapira AH (2009) Non-motor symptoms of Parkinson's disease: dopaminergic pathophysiology and treatment. Lancet Neurol 8:464-474

3. Hornykiewicz O (1966) Dopamine (3-hydroxytyramine) and brain function. Pharmacol Rev 18:925-964

4. Fahn S (2008) The history of dopamine and levodopa in the treatment of Parkinson's disease. Mov Disord 23 Suppl 3:S497-508

5. Soto $C$ (2003) Unfolding the role of protein misfolding in neurodegenerative diseases. Nat Rev Neurosci 4:49-60

6. Spillantini MG, Schmidt ML, Lee VM et al. (1997) Alpha-synuclein in Lewy bodies. Nature 388:839-840

7. Cooper AA, Gitler AD, Cashikar A et al. (2006) $\alpha$-Synuclein Blocks ERGolgi Traffic and Rab1 Rescues Neuron Loss in Parkinson's Models. Science 313:324-328

8. Ron D, Walter P (2007) Signal integration in the endoplasmic reticulum unfolded protein response. Nat Rev Mol Cell Biol 8:519-529

9. Mercado G, Valdes P, Hetz C (2013) An ERcentric view of Parkinson's disease. Trends Mol Med 19:165-175

10. Hetz C, Mollereau B (2014) Disturbance of endoplasmic reticulum proteostasis in neurodegenerative diseases. Nat Rev Neurosci 15:233249

11. Garcia-Reitbock P, Anichtchik O, Bellucci A et al. (2010) SNARE protein redistribution and synaptic failure in a transgenic mouse model of Parkinson's disease. Brain 133:2032-2044

12. Lim SY, Fox SH, Lang AE (2009) Overview of the extranigral aspects of Parkinson disease. Arch Neurol 66:167-172

13. Muller ML, Bohnen NI, Kotagal V et al. (2015) Clinical markers for identifying cholinergic deficits in Parkinson's disease. Mov Disord 30:269273

14. Perez-Lloret S, Barrantes FJ (2016) Deficits in cholinergic neurotransmission and their clinical correlates in Parkinson's disease. npj Parkinson's Disease 2:16001-16012

15. Picciotto Marina r, Higley Michael j, Mineur Yann s (2012) Acetylcholine as a Neuromodulator: Cholinergic Signaling Shapes Nervous System Function and Behavior. Neuron 76:116-129

16. Descarries L, Gisiger V, Steriade M (1997) Diffuse transmission by acetylcholine in the CNS. Prog.Neurobiol. 53:603-625

17. Descarries L, Parent M (2014) Chapter Fourteen - Asynaptic and Synaptic Innervation by Acetylcholine Neurons of the Central Nervous System. In: Pickel V, Segal M (eds) The Synapse. Academic Press, Boston, p 447-466

18. Newman EL, Gupta K, Climer JR et al. (2012) Cholinergic modulation of cognitive processing: insights drawn from computational models.

Frontiers in Behavioral Neuroscience 6 
19. Mesulam MM, Mufson EJ, Wainer BH et al. (1983) Central cholinergic pathways in the rat: an overview based on an alternative nomenclature (Ch1-Ch6). Neuroscience 10:1185-1201

20. Nys M, Kesters D, Ulens C (2013) Structural insights into Cys-loop receptor function and ligand recognition. Biochem Pharmacol 86:10421053

21. Barrantes FJ (2015) Phylogenetic conservation of protein-lipid motifs in pentameric ligand-gated ion channels. Biochimica et Biophysica Acta (BBA) - Biomembranes 1848:1796-1805

22. Wess $\mathrm{J}$ (2003) Novel insights into muscarinic acetylcholine receptor function using gene targeting technology. Trends Pharmacol Sci 24:414420

23. Raiteri M, Leardi R, Marchi M (1984) Heterogeneity of presynaptic muscarinic receptors regulating neurotransmitter release in the rat brain. J Pharmacol Exp Ther 228:209-214

24. Wess J, Duttaroy A, Zhang W et al. (2003) M1-M5 muscarinic receptor knockout mice as novel tools to study the physiological roles of the muscarinic cholinergic system. Receptors Channels 9:279-290

25. Karlin A (2002) Emerging structure of the nicotinic acetylcholine receptors. Nat.Rev.Neurosci. 3:102-114

26. Cecchini M, Changeux J-P (2015) The nicotinic acetylcholine receptor and its prokaryotic homologues: Structure, conformational transitions \&amp; allosteric modulation. Neuropharmacology 96, Part B:137-149

27. Gotti C, Riganti L, Vailati S et al. (2006) Brain neuronal nicotinic receptors as new targets for drug discovery. Curr Pharm Des 12:407-428

28. Gotti C, Moretti M, Bohr I et al. (2006) Selective nicotinic acetylcholine receptor subunit deficits identified in Alzheimer's disease, Parkinson's disease and dementia with Lewy bodies by immunoprecipitation. Neurobiology of Disease 23:481-489

29. Bordia T, Mcgregor M, Mcintosh JM et al. (2015) Evidence for a role for alpha6 ( ${ }^{*}$ nAChRs in I-dopa-induced dyskinesias using Parkinsonian alpha6 ( *) nAChR gain-of-function mice. Neuroscience 295:187-197

30. Luo R, Janssen MJ, Partridge JG et al. (2013) Direct and GABAmediated indirect effects of nicotinic ACh receptor agonists on striatal neurones. J Physiol 591:203-217

31. Zoli M, Pistillo F, Gotti C (2015) Diversity of native nicotinic receptor subtypes in mammalian brain. Neuropharmacology 96, Part B:302-311

32. Kaiser S, Wonnacott S (2000) alpha-bungarotoxin-sensitive nicotinic receptors indirectly modulate $[(3) \mathrm{H}]$ dopamine release in rat striatal slices via glutamate release. Mol Pharmacol 58:312-318

33. Alkondon M, Pereira EFR, Barbosa CTF et al. (1997) Neuronal nicotinic acetylcholine receptor activation modulates $\gamma$-aminobutyric acid release from CA1 neurons of rat hippocampal slices. J.Pharmacol.Exp.Ther. 283:1396-1411

34. Halliday GM, Leverenz JB, Schneider JS et al. (2014) The neurobiological basis of cognitive impairment in Parkinson's disease. Mov Disord 29:634-650

35. Hasselmo ME, Wyble BP, Wallenstein GV (1996) Encoding and retrieval of episodic memories: role of cholinergic and GABAergic modulation in the hippocampus. Hippocampus 6:693-708 
36. Palma E, Conti L, Roseti C et al. (2012) Novel approaches to study the involvement of alpha7-nAChR in human diseases. Curr Drug Targets 13:579-586

37. Wallace TL, Porter RH (2011) Targeting the nicotinic alpha7 acetylcholine receptor to enhance cognition in disease. Biochem Pharmacol 82:891-903

38. Quik M, Zhang D, Mcgregor M et al. (2015) Alpha7 nicotinic receptors as therapeutic targets for Parkinson's disease. Biochem Pharmacol

39. Flynn DD, Mash DC (1986) Characterization of L-[3H]nicotine binding in human cerebral cortex: comparison between Alzheimer's disease and the normal. J Neurochem. 47:1948-1954

40. Burghaus L, Schutz U, Krempel U et al. (2000) Quantitative assessment of nicotinic acetylcholine receptor proteins in the cerebral cortex of Alzheimer patients. Brain Res.Mol.Brain Res. 76:385-388

41. Freedman R, Olincy A, Buchanan RW et al. (2008) Initial phase 2 trial of a nicotinic agonist in schizophrenia. Am J Psychiatry 165:1040-1047

42. Barrantes FJ (1998) Molecular pathology of the nicotinic acetylcholine receptor. In: Barrantes FJ (ed) The nicotinic acetylcholine receptor: current views and future trends. Landes Bioscience, Austin,Texas, p 175213

43. Aubert I, Araujo DM, Cécyre D et al. (1992) Comparative alterations of nicotinic and muscarinic binding sites in Alzheimer's and Parkinson's diseases. J.Neurochem. 58:529-541

44. Banerjee C, Nyengaard JR, Wevers A et al. (2000) Cellular expression of alpha7 nicotinic acetylcholine receptor protein in the temporal cortex in Alzheimer's and Parkinson's disease--a stereological approach. Neurobiol Dis 7:666-672

45. Valles AS, Borroni MV, Barrantes FJ (2014) Targeting brain alpha7 nicotinic acetylcholine receptors in Alzheimer's disease: rationale and current status. CNS Drugs 28:975-987

46. Nikiforuk A, Kos T, Potasiewicz A et al. (2015) Positive allosteric modulation of alpha 7 nicotinic acetylcholine receptors enhances recognition memory and cognitive flexibility in rats. European Neuropsychopharmacology 25:1300-1313

47. Sadigh-Eteghad S, Talebi M, Mahmoudi J et al. (2015) Selective activation of alpha7 nicotinic acetylcholine receptor by PHA-543613 improves Abeta25-35-mediated cognitive deficits in mice. Neuroscience 298:81-93

48. Beatty WW, Butters N, Janowsky DS (1986) Patterns of memory failure after scopolamine treatment: implications for cholinergic hypotheses of dementia. Behav Neural Biol 45:196-211

49. Ostfeld AM, Aruguete A (1962) Central nervous system effects of hyoscine in man. $\mathrm{J}$ Pharmacol Exp Ther 137:133-139

50. Lin CH, Lung HL, Li ST et al. (2014) Delirium after transdermal scopolamine patch in two children. J Neuropsychiatry Clin Neurosci 26:E01-02

51. Gerretsen P, Pollock BG (2011) Drugs with anticholinergic properties: a current perspective on use and safety. Expert Opin Drug Saf 10:751-765 
52. Pappas BA, Bayley PJ, Bui BK et al. (2000) Choline acetyltransferase activity and cognitive domain scores of Alzheimer's patients. Neurobiol Aging 21:11-17

53. Minger SL, Esiri MM, Mcdonald B et al. (2000) Cholinergic deficits contribute to behavioral disturbance in patients with dementia. Neurology 55:1460-1467

54. Francis PT, Palmer AM, Snape M et al. (1999) The cholinergic hypothesis of Alzheimer's disease: a review of progress. J Neurol Neurosurg Psychiatry 66:137-147

55. Babic T (1999) The cholinergic hypothesis of Alzheimer's disease: a review of progress. J Neurol Neurosurg Psychiatry 67:558

56. Barage SH, Sonawane KD (2015) Amyloid cascade hypothesis: Pathogenesis and therapeutic strategies in Alzheimer's disease. Neuropeptides 52:1-18

57. Kar S, Slowikowski SP, Westaway D et al. (2004) Interactions between beta-amyloid and central cholinergic neurons: implications for Alzheimer's disease. J Psychiatry Neurosci. 29:427-441

58. Kar S, Slowikowski SP, Westaway D et al. (2004) Interactions between beta-amyloid and central cholinergic neurons: implications for Alzheimer's disease. J Psychiatry Neurosci 29:427-441

59. Park HE, Park IS, Oh YS et al. (2015) Subcortical whiter matter hyperintensities within the cholinergic pathways of patients with dementia and parkinsonism. J Neurol Sci 353:44-48

60. Gaspar P, Gray F (1984) Dementia in idiopathic Parkinson's disease. A neuropathological study of 32 cases. Acta Neuropathol 64:43-52

61. Lee JE, Cho KH, Song SK et al. (2014) Exploratory analysis of neuropsychological and neuroanatomical correlates of progressive mild cognitive impairment in Parkinson's disease. J Neurol Neurosurg Psychiatry 85:7-16

62. Hall H, Reyes S, Landeck $\mathrm{N}$ et al. (2014) Hippocampal Lewy pathology and cholinergic dysfunction are associated with dementia in Parkinson's disease. Brain 137:2493-2508

63. Lorenz R, Samnick S, Dillmann U et al. (2014) Nicotinic alpha4beta2 acetylcholine receptors and cognitive function in Parkinson's disease. Acta Neurol Scand 130:164-171

64. Liu AK, Chang RC, Pearce RK et al. (2015) Nucleus basalis of Meynert revisited: anatomy, history and differential involvement in Alzheimer's and Parkinson's disease. Acta Neuropathol 129:527-540

65. Lieberman A (2006) Are dementia and depression in Parkinson's disease related? J Neurol Sci 248:138-142

66. Bohnen NI, Kaufer DI, Hendrickson R et al. (2007) Cortical cholinergic denervation is associated with depressive symptoms in Parkinson's disease and parkinsonian dementia. J Neurol Neurosurg Psychiatry 78:641-643

67. Shoji Y, Nishio Y, Baba T et al. (2014) Neural substrates of cognitive subtypes in Parkinson's disease: a 3-year longitudinal study. PLoS One 9:e110547

68. Yarnall A, Rochester L, Burn DJ (2011) The interplay of cholinergic function, attention, and falls in Parkinson's disease. Mov Disord 26:24962503 
69. Takahashi S, Tohgi $\mathrm{H}$, Yonezawa $\mathrm{H}$ et al. (1999) The effect of trihexyphenidyl, an anticholinergic agent, on regional cerebral blood flow and oxygen metabolism in patients with Parkinson's disease. J Neurol Sci 167:56-61

70. Lenzi GL, Jones T, Reid JL et al. (1979) Regional impairment of cerebral oxidative metabolism in Parkinson's disease. J Neurol Neurosurg Psychiatry 42:59-62

71. Manganelli F, Vitale C, Santangelo G et al. (2009) Functional involvement of central cholinergic circuits and visual hallucinations in Parkinson's disease. Brain 132:2350-2355

72. Vardy ER, Teodorczuk A, Yarnall AJ (2015) Review of delirium in patients with Parkinson's disease. J Neurol

73. Crispo JA, Willis AW, Thibault DP et al. (2016) Associations between Anticholinergic Burden and Adverse Health Outcomes in Parkinson Disease. PLoS One 11:e0150621

74. Van Dort CJ, Zachs DP, Kenny JD et al. (2015) Optogenetic activation of cholinergic neurons in the PPT or LDT induces REM sleep. Proc Natl Acad Sci U S A 112:584-589

75. Suzuki K, Miyamoto M, Miyamoto T et al. (2015) Parkinson's disease and sleep/wake disturbances. Curr Neurol Neurosci Rep 15:8

76. Postuma RB, Lang AE, Massicotte-Marquez J et al. (2006) Potential early markers of Parkinson disease in idiopathic REM sleep behavior disorder. Neurology 66:845-851

77. Laloux C, Derambure P, Jacquesson JM et al. (2007) The effects of serotoninergic, noradrenergic, cholinergic and dopaminergic drugs on vigilance states in MPTP-treated mice. Brain Res 1161:79-87

78. Nardone R, Bergmann J, Brigo F et al. (2013) Functional evaluation of central cholinergic circuits in patients with Parkinson's disease and REM sleep behavior disorder: a TMS study. J Neural Transm 120:413-422

79. Pagano G, Rengo G, Pasqualetti G et al. (2014) Cholinesterase inhibitors for Parkinson's disease: a systematic review and metaanalysis. J Neurol Neurosurg Psychiatry

80. Emre M, Aarsland D, Albanese A et al. (2004) Rivastigmine for dementia associated with Parkinson's disease. N Engl J Med 351:2509-2518

81. Dubois B, Tolosa E, Katzenschlager R et al. (2012) Donepezil in Parkinson's disease dementia: a randomized, double-blind efficacy and safety study. Mov Disord 27:1230-1238

82. Ravina B, Putt M, Siderowf A et al. (2005) Donepezil for dementia in Parkinson's disease: a randomised, double blind, placebo controlled, crossover study. J Neurol Neurosurg Psychiatry 76:934-939

83. Emre M, Poewe W, De Deyn PP et al. (2014) Long-term safety of rivastigmine in parkinson disease dementia: an open-label, randomized study. Clin Neuropharmacol 37:9-16

84. Seppi K, Weintraub D, Coelho M et al. (2011) The Movement Disorder Society Evidence-Based Medicine Review Update: Treatments for the non-motor symptoms of Parkinson's disease. Mov Disord 26 Suppl 3:S42-80

85. Mamikonyan E, Xie SX, Melvin E et al. (2015) Rivastigmine for mild cognitive impairment in Parkinson disease: a placebo-controlled study. Mov Disord 30:912-918 
86. Possin KL, Kang GA, Guo C et al. (2013) Rivastigmine is associated with restoration of left frontal brain activity in Parkinson's disease. Mov Disord 28:1384-1390

87. Hindle JV (2013) The practical management of cognitive impairment and psychosis in the older Parkinson's disease patient. J Neural Transm (Vienna) 120:649-653

88. Bergman J, Lerner V (2002) Successful use of donepezil for the treatment of psychotic symptoms in patients with Parkinson's disease. Clin Neuropharmacol 25:107-110

89. Schrag A, Sauerbier A, Chaudhuri KR (2015) New clinical trials for nonmotor manifestations of Parkinson's disease. Mov Disord 30:14901504

90. Tampi RR, Tampi DJ, Ghori AK (2016) Acetylcholinesterase Inhibitors for Delirium in Older Adults. Am J Alzheimers Dis Other Demen 31:305-310

91. Aurora RN, Zak RS, Maganti RK et al. (2010) Best practice guide for the treatment of REM sleep behavior disorder (RBD). J Clin Sleep Med 6:8595

92. Howell MJ, Schenck CH (2015) Rapid Eye Movement Sleep Behavior Disorder and Neurodegenerative Disease. JAMA Neurol 72:707-712

93. Arnulf I, Ferraye M, Fraix V et al. (2010) Sleep induced by stimulation in the human pedunculopontine nucleus area. Ann Neurol 67:546-549

94. Bohnen NI, Albin RL (2011) The cholinergic system and Parkinson disease. Behav Brain Res 221:564-573

95. Chung KA, Lobb BM, Nutt JG et al. (2010) Effects of a central cholinesterase inhibitor on reducing falls in Parkinson disease. Neurology 75:1263-1269

96. Henderson EJ, Lord SR, Brodie MA et al. (2016) Rivastigmine for gait stability in patients with Parkinson's disease (ReSPonD): a randomised, double-blind, placebo-controlled, phase 2 trial. Lancet Neurol 15:249-258

97. Bohnen NI, Frey KA, Studenski S et al. (2013) Gait speed in Parkinson disease correlates with cholinergic degeneration. Neurology 81:16111616

98. Bohnen NI, Muller ML, Koeppe RA et al. (2009) History of falls in Parkinson disease is associated with reduced cholinergic activity. Neurology 73:1670-1676

99. Zahodne LB, Fernandez HH (2008) Pathophysiology and treatment of psychosis in Parkinson's disease: a review. Drugs Aging 25:665-682 
Table 1. Most abundant acetylcholine receptors expressed in the CNS.

\begin{tabular}{|c|c|c|c|c|c|}
\hline $\begin{array}{l}\text { Pharmacol. } \\
\text { type } \\
\text { Common } \\
\text { denominati } \\
\text { on }\end{array}$ & \multicolumn{2}{|c|}{$\begin{array}{l}\text { Metabotropic } \\
\text { Muscarinic }\end{array}$} & \multicolumn{3}{|c|}{$\begin{array}{l}\text { Ionotropic* } \\
\text { Nicotinic }\end{array}$} \\
\hline Subtype & M2,M4 & $\begin{array}{l}\text { M1 (50-60\% } \\
\text { of the total } \\
\text { mAChRs), } \\
\text { M3, M5 }\end{array}$ & $\begin{array}{l}\text { hetero- } \\
\text { pentameric } \\
\text { ( } \alpha 4 \text { and } \beta 2 \\
\text { subunits) }\end{array}$ & $\begin{array}{l}\text { homo- } \\
\text { pentameric } \\
\text { receptor (only } \\
\alpha 7 \text { subunits) }\end{array}$ & $\begin{array}{l}\text { hetero- } \\
\text { pentameri } \\
c(\alpha 6 \text { and } \\
\beta 2 \\
\text { subunits) }\end{array}$ \\
\hline $\begin{array}{l}\text { Second } \\
\text { messenger } \\
\mathrm{s}\end{array}$ & $\begin{array}{l}\mathrm{G}_{\mathrm{i} / \mathrm{o}} \text { protein, } \\
\text { inhibition of } \mathrm{AC}\end{array}$ & $\begin{array}{l}\text { Gq protein, } \\
\text { metabolic } \\
\text { cascades }\end{array}$ & $\begin{array}{l}\text { increased } \mathrm{Na}^{+} \\
\text {and } \mathrm{K}^{+} \\
\text {permeability }\end{array}$ & $\begin{array}{l}\text { increased } \\
\mathrm{Ca}^{2+}, \mathrm{Na}^{+} \text {and } \mathrm{K}^{+} \\
\text {permeability }\end{array}$ & $\begin{array}{l}\text { increased } \\
\mathrm{Na}^{+} \text {and } \\
\mathrm{K}^{+} \\
\text {permeabili } \\
\text { ty }\end{array}$ \\
\hline Localization & $\begin{array}{l}\text { Presynaptic } \\
\text { (M2/4). } \\
\text { hippocampus } \\
\text { and cerebral } \\
\text { cortex, } \\
\text { pedunculoponti } \\
\text { ne and } \\
\text { laterodorsal } \\
\text { tegmental } \\
\text { nuclei of the } \\
\text { mesopontine } \\
\text { tegmentum } \\
\text { (M2), striatum } \\
\text { (M4), co- } \\
\text { localized with } \\
\text { dopamine } \\
\text { receptors }\end{array}$ & $\begin{array}{l}\text { Predominant } \\
\text { ly } \\
\text { extrasynapti } \\
\text { c in } \\
\text { forebrain, } \\
\text { hippocampu } \\
\text { s, cerebral } \\
\text { cortex, } \\
\text { striatum, } \\
\text { thalamus } \\
\text { (M1). } \\
\text { Hypothalam } \\
\text { us and } \\
\text { various } \\
\text { other brain } \\
\text { regions } \\
\text { (M3). Pars } \\
\text { compacta of } \\
\text { the } \\
\text { substantia } \\
\text { nigra, } \\
\text { ventral } \\
\text { tegmental } \\
\text { area (M5) }\end{array}$ & $\begin{array}{l}90 \% \text { of the } \\
\text { high-affinity } \\
\text { nAChR in } \\
\text { brain: } \\
\text { localized in } \\
\text { cortex, } \\
\text { hippocampus, } \\
\text { striatum, } \\
\text { thalamus, } \\
\text { superior } \\
\text { colliculus and } \\
\text { mesencephalo } \\
\text { n. }\end{array}$ & $\begin{array}{l}\text { involved in } \\
\text { classic } \\
\text { excitatory } \\
\text { neurotransmissi } \\
\text { on in some } \\
\text { brain regions } \\
\text { where the } \\
\text { release of } \\
\text { neurotransmitter } \\
\text { s, neurite } \\
\text { outgrowth and } \\
\text { neuronal } \\
\text { survivalis also } \\
\text { modulated }\end{array}$ & $\begin{array}{l}\text { Mesostriat } \\
\text { al } \\
\text { pathway, } \\
\text { substantia } \\
\text { nigra, } \\
\text { ventral } \\
\text { tegmental } \\
\text { area, } \\
\text { nucleus } \\
\text { accumben } \\
\text { s, } \\
\text { caudate- } \\
\text { putamen, } \\
\text { visual } \\
\text { pathways }\end{array}$ \\
\hline
\end{tabular}

$\mathrm{AC}=$ adenylate cyclase

* Only neuronal-type receptors present in the CNS are included.

Subtypes listed correspond to the most frequently found combination of

subunits. ${ }^{*}$ See the particular case of the heteromeric $\alpha 7 \beta 2$ in the text.

For further reference see Refs. [15, 22, 24, 25, 32, 33]. 
Table 2. Sources of cholinergic dysfunction in PD and its main clinical correlates.

\begin{tabular}{ll}
\hline PD feature & Pathological basis \\
\hline Cognitive Impairment & Degeneration of the \\
& NBM \\
REM sleep behavior & Degeneration of the \\
disorder & PPN \\
Psychosis & Reduced cholinergic \\
& tone (maybe PPN) \\
\hline
\end{tabular}

NBM= Nucleus Basalis Magnocellularis (Meynert's nucleus); PPN= Pedunculopontine nucleus. 
Table 3. Studies with cholinesterase inhibitors for cognitive impairmentin PD.

\begin{tabular}{|c|c|c|c|c|}
\hline Author \& Year & $\begin{array}{l}\text { Drug/ } \\
\text { Procedure }\end{array}$ & Design & Sample & Main results \\
\hline Emre 2004 [80] & Rivastigmine & $\begin{array}{l}\text { Randomized, } \\
\text { double-blind, } \\
\text { placebo- } \\
\text { controlled trial }\end{array}$ & $\begin{array}{l}541 \text { demented } \\
\text { PD patients }\end{array}$ & $\begin{array}{l}\text { Improvement of } \\
2.1 \text { points in the } \\
\text { ADAS-cog with } \\
\text { rivastigmine vs } \\
0.7 \text {-point } \\
\text { worsening with } \\
\text { placebo }(p<0.001)\end{array}$ \\
\hline Ravina 2005 [82] & Donepezil & $\begin{array}{l}\text { Randomized, } \\
\text { double-blind, } \\
\text { placebo- } \\
\text { controlled trial }\end{array}$ & $\begin{array}{l}22 \text { demented } \\
\text { PD }\end{array}$ & $\begin{array}{l}\text { There was a } 1.9 \\
\text { point trend toward } \\
\text { better scores on } \\
\text { the ADAS-cog on } \\
\text { donepezil vs } \\
\text { placebo ( } p=N S)\end{array}$ \\
\hline Dubois 2012 [81] & Donepezil & $\begin{array}{l}\text { Randomized, } \\
\text { double-blind, } \\
\text { placebo- } \\
\text { controlled trial }\end{array}$ & $\begin{array}{l}355 \text { demented } \\
\text { PD }\end{array}$ & $\begin{array}{l}\text { In a post-hoc } \\
\text { analysis, } \\
\text { donepezil was } \\
\text { better than } \\
\text { placebo }\end{array}$ \\
\hline $\begin{array}{l}\text { Mamikonyan } 2015 \\
\text { [85] }\end{array}$ & Rivastigmine & $\begin{array}{l}\text { Randomized, } \\
\text { double-blind, } \\
\text { placebo- } \\
\text { controlled trial }\end{array}$ & $\begin{array}{l}28 \text { PD patients } \\
\text { with minimal } \\
\text { cognitive } \\
\text { impairment }\end{array}$ & $\begin{array}{l}\text { Non-significant } \\
\text { benefits with } \\
\text { rivastigmine }\end{array}$ \\
\hline
\end{tabular}

PPN DBS= Deep Brain stimulation of the Pedunculo-pontine Tegmental Nuclei. 